Original Article

\title{
Design, development, and clinical validation of therapeutic toys for autistic children
}

\author{
Kevin C. Tseng, PhD ${ }^{1-3)}$, Sung-Hui Tseng, PhD ${ }^{4,5)}$, Hsin-Yi Kathy Cheng, $\mathrm{PhD}^{3,}$ 6)* \\ 1) Product Design and Development Laboratory, Department of Industrial Design, \\ College of Management, Chang Gung University, Taiwan \\ 2) Healthy Aging Research Center, Chang Gung University, Taiwan \\ 3) Department of Physical Medicine and Rehabilitation, Chang Gung Memorial Hospital, Taiwan \\ 4) School of Medicine, College of Medicine, Taipei Medical University, Taiwan \\ 5) Department of Physical Medicine and Rehabilitation, Taipei Medical University Hospital, Taiwan \\ 6) Graduate Institute of Early Intervention, College of Medicine, Chang Gung University: \\ No. 259 Wenhua 1st Rd., Kwei-Shan, Tao-Yuan City 333, Taiwan
}

\begin{abstract}
Purpose] One of the characteristics of autistic children is social interaction difficulties. Although therapeutic toys can promote social interaction, however its related research remains insufficient. The aim of the present study was to build a set of cooperative play toys that are suitable for autistic children. [Subjects and Methods] This study used an innovative product design and development approach as the basis for the creation of cooperative play toys. [Results] The present study has successfully developed cooperative play toys. Compared to the traditional game therapy for autism, cooperative play toy therapy can significantly improve the interactions between autistic children and their peers. [Conclusion] The most critical design theme of cooperative play toys focuses on captivating the interest of autistic children. Based on the needs of the individual cases, the design of the therapeutic toy set was specifically tailored, i.e., by reinforcing the sound and light effects to improve the attractiveness of the toys. In the future, different play modes can be combined with this toy set to further enhance the degree of interaction of autistic children and improve their quality of life and social skills.

Key words: Assistive technology, Autism, Play therapy
\end{abstract}

(This article was submitted Jan. 18, 2016, and was accepted Apr. 7, 2016)

\section{INTRODUCTION}

Autism is a neuro-developmental disorder that is characterized by the following symptoms: the impairment of social development and verbal communication, repetitive movement, and restricted behavior. These symptoms cause the patients to experience severe difficulties with social interaction, life skills, and environmental adaptation. Autism spectrum disorders (ASDs) are now considered to be among the most prevalent and debilitating developmental disabilities ${ }^{1}$. According to a report by the United States Centers for Disease Control and Prevention (CDC), there are approximately 67 million autistic patients worldwide; in other words, there is one autistic patient for every 110 healthy individuals ${ }^{2}$. Children with ASD present with a range of symptomatology. The core features of ASD include deficits in communication and social skills, as well as restricted interests/repetitive behaviors ${ }^{3}$. The children's deviant behaviors, such as making noises, and being irritable and aggressive, often act as a barrier between the children and their family members, friends, and counseling personnel. Consequently, the treatment decisions are complex and diverse. The present study aimed primarily to help autistic children to experience healthy growth and development and improve their language ability, behavior, and social interaction. Because the level of language ability and intelligence was considered in the experiments, only high-functioning children with ASD

*Corresponding author. Hsin-Yi Kathy Cheng (E-mail: kcheng@mail.cgu.edu.tw)

(C2016 The Society of Physical Therapy Science. Published by IPEC Inc.

This is an open-access article distributed under the terms of the Creative Commons Attribution Non-Commercial No Derivatives (by-nc-nd) License $<$ http://creativecommons.org/licenses/by-nc-nd/4.0/>. 
was recruited to participate in this study.

Individuals with high-functioning autism spectrum disorders (HFASD) have different characteristics, strengths, and needs compared to individuals with moderate-to-severe autism. HFASD individuals are characterized by a nearly normal language ability and intelligence; however, they do have social and pragmatic impairments. Researchers from Yale University have defined individuals with HFASD as individuals with autism who have a full-scale IQ greater than 70 and do not have significant language and intellectual delays ${ }^{4}$. These individuals demonstrate the typical symptoms of autism as young children. As they grow older, they gradually show greater degrees of cognition as well as social and adaptive behavioral skills, and have good long-term clinical outcomes compared to children who are diagnosed with moderate-to-severe autism.

Although individuals with HFASD undergo nearly normal intellectual and language development, researchers have found that the cognitive development within this group is uneven ${ }^{5}$. Early intervention in patients with autism can effectively improve symptoms. Earlier intervention with therapy generally results in more significant improvements ${ }^{6}$. At present, clinical studies of autistic children primarily focus on interaction, education, and psychological control ${ }^{7-12)}$. For example, applied behavior analysis is an approach that achieves a goal in stages by using tokens and prizes as incentives to guide the patients to generate spontaneous behavior; then, the behavior is analyzed to improve their interaction and adaptation abilities ${ }^{13)}$. The structured treatment and education of autistic and related communication-handicapped children (TEACCH) program and music therapy have also been used to attract the attention of autistic children ${ }^{14,15)}$. In recent years, investigating the play characteristics of autistic children has been considered to be an important method for understanding the pathology of autism, and more studies have been conducted using this type of play method. It uses an approach in which autistic children can use body function to express inherent emotion to achieve interactive communication, thereby establishing interpersonal skills and fostering social adaptation ${ }^{16)}$. However, given that they are limited by the difficulties of interaction and communication, autistic children mainly play alone, rarely interacting with other people; thus, their play patterns tend to be rather fixed and repetitive.

Compared to neurotypical children, the play behavior of autistic children often reveals an attachment to a specific toy and/ or inappropriate use of toys, and spontaneous interactive play and social imitation games are lacking ${ }^{17)}$. Therefore, Wolfberg and Schuler have proposed integrated play groups to allow autistic children to overcome obstacles and enhance interaction with the help and guidance of their peers ${ }^{18)}$. Playing with the peers can help autistic children in terms of promoting the growth of self-concept ${ }^{19)}$ and personality adaptation ${ }^{20)}$, as well as the development of language, thinking ${ }^{21)}$, and problem-solving skills $^{22}$. However, although interaction with peers through playing games can help autistic children reduce improper social behavior and improve interactive ability, the majority of these studies still list autistic children as the "being helped" who must wait for assistance from their peers, instead of using the "initiative" ability. Therefore, an equal and mutually assisting relationship cannot be established. However, there is still a lack of commercially available games for autistic children and a lack of discussion about therapeutic toys; in particular, the availability of cooperative play toys, which emphasize the interaction between peers, remains limited.

Therefore, the objective of this study was to develop a set of cooperative play toys that are suitable for autistic children, thereby promoting interaction of autistic children with their peers, enhancing their ability to study interpersonal interactions actively, and reducing improper social behavior so that effective early intervention can be achieved. The present study used an innovative product design and development approach (IPDD) ${ }^{23}$ ) to develop cooperative play toys for children with autism. At the concept generation stage, therapists' suggestions and the needs of autistic children determined through our observations were incorporated to develop the cooperative play toys. Persona and scenario design were used to generate the prototype of the toys. Finally, the predicted effects of the cooperative play toys were expertly evaluated and verified using the Penn interactive peer play scale (PIPPS) ${ }^{24)}$.

\section{SUBJECTS AND METHODS}

The present study used the IPDD method. Multiple interdisciplinary analyses and methods were integrated to identify potential demand and develop market positioning, design features, and engineering solutions ${ }^{23,25)}$. This study protocol was approved by the institutional review board of Taipei Medical University Hospital (No. CRC-11-11-02). Written informed consent was obtained from the legal guardians of the participating children.

A single case test method was used for the study. Two groups of children were recruited to play together. To test the effect of the cooperative play toys on the interactive relationship between the autistic children and their neurotypical peers, the present study introduced the cooperative play toys into the autism play treatment process. Then, social interaction behavior analysis $^{26)}$ and PIPPS ${ }^{24)}$ were used to assess the changes in the interaction between autistic children and their peers during play and the effectiveness of the cooperative play toys in promoting this interaction.

A therapist engaged an autistic child and a neurotypical child in the play therapy process. The neurotypical child and the therapist served to guide and improve the social interactive ability of the autistic child.

The experiment was divided into a general play treatment mode and a cooperative play treatment mode. The traditional play therapy process and the cooperative play toy therapy process each lasted 20 minutes. The experimental process was repeated four times, once each week, lasting for a total of 1 month. First, the therapist guided the normal child and the autistic child to undergo the traditional play therapy process. After the therapy process, the therapist completed the PIPPS 
questionnaire to determine the degree of interaction between the autistic child and his/her peer. Then, the therapist guided the children to undergo treatment according to the cooperative play toy therapy process. Similarly, after the treatment, the therapist completed the questionnaire, which was used as the basis for the subsequent analysis. Because the present study investigated the interaction, the first stage of play with the cooperative play toy was not included in the experimental procedure. During the test, a hidden camera and a microphone were used to record the interaction between the children, which served as the basis for the social interaction analysis. The present study hypothesized that, compared to the general autism play therapy toys, the autism cooperative play toys could significantly improve the interaction between autistic children and their neurotypical peers.

According to the PIPPS results, the present study required a paired t-test to analyze the improvement in the interaction before and after the introduction of the cooperative play toys, i.e., the difference between the general play therapy mode and the cooperative play therapy mode. The social interaction behavior analysis method uses $\mathrm{C}$ statistics to compare the effectiveness of active behavior and responsive behavior between the traditional play therapy and the cooperative play toy therapy.

\section{RESULTS}

Prototype development stage 1 (persona method and scenario design method): In this stage, two 4- and 6-year-old children with high-functioning autism were the subjects of this analysis. Table 1 shows the profile results of the subjects and the description of the scenario design. Of these factors, regardless of the amount of opportunities (educational setting and whether the child was an only child) for the subjects to interact with other people, the lack of verbal interaction, repetitive movements, the expression of uncertainty in their eyes, irritability, and playing games alone were the most significant features of behavior of the autistic children. Additionally, the major social barriers of these children included the lack of verbal interaction, presence of repetitive movements, the lack of interest in other things, the lack of eye contact, the difficult in expression, and the inability to establish friendships with peers. Hence, a reasonable solution (Table 2) may be to guide the children to take turns to ask and answer questions, guide the children seek to assistance actively, to provide periodic difficulty modes to add sound and light effects, to note the appearance design of the product, and to engage in cooperative play mode.

Table 1. The profiles of two autistic children and the description of the scenario interaction mode

\begin{tabular}{|c|c|c|c|}
\hline Name & ASD001 & Name & ASD002 \\
\hline & & & sand \\
\hline $\mathrm{Ed}$ & & 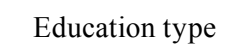 & \\
\hline $\begin{array}{l}\text { Whether single } \\
\text { child }\end{array}$ & No & & \\
\hline Toy type & Building block & loy & Matching type toy \\
\hline & & & \\
\hline \multicolumn{2}{|c|}{$\begin{array}{l}\text { Scenario description: } \\
\text { ASD001 was diagnosed as an autism patient at 1-year-old. } \\
\text { He is very silent, and he maintains a distance from his } \\
\text { family. He rarely interacts with his family members, including } \\
\text { his brother and sister, and he lacks verbal communication. } \\
\text { His mother attempted to use different types of games and toys } \\
\text { to entice him to interact with family members. However, the } \\
\text { way he plays games is very fixed and dull. Apart from } \\
\text { occasionally making strange sounds, he likes to repeat his } \\
\text { older brother's gameplay and movements. Sometimes, his } \\
\text { older brother wants to play with him, but he does not know } \\
\text { how to guide him. Therefore, their mother bought several } \\
\text { toys that are suitable for two people to play, such as Monopoly } \\
\text { and playing house. However, ASD001 was not interested in } \\
\text { these games, and at times he did not follow the game rules } \\
\text { and even lost his temper and destroyed the games. Eventually, } \\
\text { the brothers played the games by themselves, and they rarely } \\
\text { interacted. } \\
\text { Social barriers: lack of interactive capabilities, lack of verbal } \\
\text { interaction, lack of concentration, lack of interest. }\end{array}$} & \multicolumn{2}{|c|}{$\begin{array}{l}\text { Scenario description: } \\
\text { ASD002 was a 6-year-old autistic child; he is currently in } \\
\text { a lower kindergarten class. He does not know how to interact } \\
\text { with other people. He frequently looks at other places when he } \\
\text { is talking. Sometimes, he makes the teacher think that he is not } \\
\text { concentrating, and other children also tend to misunderstand him } \\
\text { as being indifferent and lacking manners. In addition, he does } \\
\text { not know how to express himself. Thus, when other people do } \\
\text { not understand what he is thinking, he loses his temper or dis- } \\
\text { plays self-injurious behaviors to vent. ASD002 has a very stub- } \\
\text { born personality; if he is obsessed with one thing, he is unable to } \\
\text { extricate himself. Similarly, with toys; he often does not want to } \\
\text { share with other people or does not want to cooperate with other } \\
\text { people, unless he needs other people's help to finish. Because he } \\
\text { often keeps the toy to himself, his peers eventually do not like to } \\
\text { play with him. Although the teacher designed many group games, } \\
\text { such as eagle catching chicken, when other kids touched his body, } \\
\text { he would suddenly scream, which scared other people. } \\
\text { Social barriers: lack of eye contact, inappropriate behavior, lack } \\
\text { of concentration, being misunderstood as indifferent or } \\
\text { deliberately ignoring others, unable to express himself, inability } \\
\text { to integrate into the group. }\end{array}$} \\
\hline
\end{tabular}


Prototype development stage 2 (individual case observation): A total of 13 HFASD boys aged $6.7 \pm 2.9$ years was recruited (Table 3). A 1-week field observation was conducted with 30 minutes observations. The treatment process can be divided into three major stages: therapist guidance, intra-treatment, and feedback. The guidance by the therapist was a warm-up activity before the treatment, and its goal was to attract the attention of the autistic children, such as by demonstrating the toys, explaining the prizes, or leading the children to perform several movements. The intra-treatment stage recorded the most important activities and events that occurred during the treatment. For example, the therapist may guide the children to mimic speech, provide appropriate assistance, and participate in the play activity. The feedback was the reward given by the therapist when the treatment was completed or when the autistic children finished a certain task. Table 4 shows the early-start Denver model (ESDM) numbering results of the therapy skills and the statistical results. The results revealed that attention

Table 2. Summarized issues and interpretation of needs

\begin{tabular}{ll}
\hline Summarized issues & Reasonable solutions \\
\hline Lack of verbal interaction & Take turns asking and answering questions, guide the children to seek help actively \\
Repetitive movement, imitation & Provide multiple game modes and variable ways to play \\
Lack of concentration & Enhance sound and light effects, use attractive appearance and bright colors \\
Lack of interest in other things & Provide periodic difficulty modes and variable ways to play \\
Lack of eye contact & Enhance sound and light effects, use attractive appearance and bright colors \\
Inappropriate behavior & Teach and guide the children \\
$\begin{array}{l}\text { Being misunderstood as indifferent or } \\
\text { deliberately overlooking others }\end{array}$ & Guide the children to seek help actively \\
$\begin{array}{l}\text { Unable to express him/herself } \\
\text { Unable to establish friendships with } \\
\text { peers or to integrate into groups }\end{array}$ & $\begin{array}{l}\text { Guide the children to seek help actively } \\
\text { Guide the children to perform interactive games with peers; establish the same goal } \\
\text { for the game }\end{array}$ \\
\hline
\end{tabular}

Table 3. Demographics of the participants

\begin{tabular}{clccc}
\hline Number & Code & Gender & Age & Therapy method \\
\hline 1 & Qianqian & male & 5 & Language therapy \\
2 & Youyou & male & 3 & Language therapy \\
3 & Xiaohua & male & 7 & Language therapy \\
4 & Ah Kuan & male & 12 & Language therapy \\
5 & Xiaotong & male & 3 & Language therapy \\
6 & Xiaohan & male & 6 & Music therapy \\
7 & Ah Kai & male & 8 & Occupational therapy \\
8 & Huahua & male & 7 & Occupational therapy \\
9 & Xiaoming & male & 10 & Occupational therapy \\
10 & Zizi & male & 3 & Language therapy \\
11 & Haohao & male & 5 & Occupational therapy \\
12 & Qiangqiang & male & 10 & Occupational therapy \\
13 & Xiaoxian & male & 8 & Occupational therapy \\
\hline
\end{tabular}

Table 4. Summary of the ESDM numbering result and number of times the therapy skills were used

\begin{tabular}{lcc}
\hline Therapy method & Times & Therapy stage \\
\hline Attention capture & 13 & Guidance \\
Behavior modeling & 9 & Feedback \\
Behavior linkage & 7 & Intra-treatment \\
Prompt & 5 & Intra-treatment \\
Assisted quitting & 4 & Intra-treatment \\
Function evaluation or behavior analysis & 4 & Intra-treatment \\
Restricting & 1 & Intra-treatment \\
\hline
\end{tabular}


capture occurred 13 times, and it occurred an average of one time per individual primarily because the therapist normally used attention capture as the guiding method after first attracting the children's interest, followed by the subsequent treatment steps. Second, in the feedback stage, the therapist modeled the behavior of the autistic children by praising or rewarding them, which occurred nine times. This process indicated that attention capture and encouragement are indispensable and important factors in the autistic children's mode of play.

The present study used social interaction characteristics to analyze the responsive behavior mode of the autistic children under the active guidance of the therapist, thereby summarizing the pitfalls of the mode of play ${ }^{26}$ ). Table 5 shows the active guidance given to the children by the therapist and the active and passive responses of the autistic children. During the treatment, the active behavior of the therapist primarily included teaching, an invitation to participate in play, and a demonstration of the materials; the main purpose of this treatment was to guide the children to perform expected behaviors or movements while simultaneously capturing the children's attention. The responses of the autistic children were mainly passive. Of the autistic children, the majority could respond to simple requests and instructions, and they could even repeat the instructions given by the therapist through mimicry. However, they demonstrated markedly less cooperation, taking turns, and language responses. Therefore, in summary, in terms of the play therapy mode for the autistic children, three major design concepts were noted. First, the game must be of the sort that is able to attract the interest and attention of the autistic children, such as puzzles and matching, which are often used by therapists. Second, a set of progressive game rules ranging from easy to difficult should be designed for autistic children and should be easily integrated into the game. Third, the game must be interrupted at an appropriate time or its difficulty must be increased to allow the autistic children to seek help actively to enhance interactive study.

Prototype development stage 3 (expert interview): During this stage, three child psychiatrists at Taipei Medical University Hospital were recruited for interviews. They each had more than 1 year of experience in treating autistic children, and they specialized in interventions related to the mind and interpersonal interactions of autistic children. The interviews were conducted in a one-on-one, semi-heuristic manner. The content of the interview theme covered the social barriers and interaction modes of autistic children, clinical treatment methods, toys used, play methods, the favorite types of toys of the autistic children and expert suggestions. The three experts' responses to each topic were summarized, and the following five design features were generated: first, the play should include fixed rules and progressive variations; second, there should be variations of toys and play modes with which the autistic children are familiar; third, sound (not too loud) and light effects can be added to the toys to attract the attention of autistic children; fourth, the game must be able to attract the autistic children while simultaneously producing opportunities for them to seek help from other people and encourage them to speak actively; fifth, the game process should require adult guidance and interaction.

Prototype development stage 4 (quality function development): Table 6 shows the quality function deployment (QFD) analysis results of the engineering strategy. The results demonstrated that the major engineering solutions of the autism cooperative play toys included matching play modes, level-type game rules, colorful acrylic animals, music, and speakers.

According to the QFD results, a complete autism cooperative play toy comprises the physical toy and the game mode. The toy uses an animal puzzle and the accompanying music control to attract the children's attention. The game mode enhances the entertainment value, variability, and difficulty level of using the cooperative play toy, hence emphasizing the cooperative nature of the game and progressively guiding the children to seek assistance actively, with a view to increasing social interaction. The prototype of the cooperative play toy system, which was developed based on the above-mentioned rules, was as follows:

Toy entity: The core of the design content of the cooperative play toy was a product image of amiability and interactivity.

Table 5. Summary of the number of active behaviors of the therapist and the responsive behavior of the autistic children

\begin{tabular}{lclc}
\hline Active behavior of the therapist & & Passive responsive behavior of autistic children & Number \\
Method & Number & Method & 10 \\
\hline Teaching & 14 & Respond to request & 8 \\
Invitation to a game & 11 & Imitation & 8 \\
Give or demonstrate material & 8 & Respond to question & 8 \\
Provide help & 6 & Follow instructions & 7 \\
Ask a question & 6 & Accept provided toy or material & 4 \\
Give instructions & 6 & Respond to cooperation & 3 \\
Ask to take a turn & 4 & Respond to taking turns & 1 \\
Ask to cooperate & 4 & Look at the person who calls him & 1 \\
Praise & 4 & Respond to language & Number \\
Ask to participate & 3 & Active responsive behavior of autistic children & 6 \\
Active conversation & 2 & Method & Ask for permission and assistance \\
Ask activity & 2 & &
\end{tabular}


The appearance design used paired graphics to attract autistic children. In terms of color usage, the major body was half white and half aqua blue for the game space. It was shaped like a round ball, accompanied by eight animal building blocks, which that are a favorite of children. The cooperative play toy was a musical-type play toy for two people, including a neurotypical child and an autistic child. The toy plays the same piece of music to achieve the goal of cooperation. Moreover, the use of paired graphics enhanced the visual response ability of the autistic children. The autism cooperative play toy can be divided into three parts: major body appearance, button structures, and electronic mechanism. Colorful acrylic animal puzzles were used to coordinate the subsequent diversity game mode. The electronic structure was composed of LED, music IC, speakers, and other electronic elements, which were mounted on the holder. When the child presses the animal-shaped acrylic button, the cooperative play toy makes the sound of an octave (one cooperative play toy can control four notes; one set has eight notes). Thus, eight animals and eight colored lights exhibit the sound, light, and electronic mechanisms. The button structures and the acrylic graphics can be changed to other graphics to enhance attraction and correspond to the preferences of different children. The game rules and music score difficulty can be changed depending on the child's age and familiarity.

Game mode: There are three game levels, based on difficulty. In level 1, under the guidance of the therapist, the autistic children match the animal building block graphic and color, and they independently play simple music, thus allowing the autistic children to become familiar with the use and game process of the cooperative play toy. In level 2, a neurotypical child and an autistic child play together using the cooperative play toy. Both children must follow the therapist's instructions and play the music according to the simplified graphic score. The simplified score uses the animal shapes on the cooperative play toy as notes, and the children participating in the game only need to play according to the order of the animal graphics shown; this allows them to finish the song. Because one cooperative play toy only controls four notes, the children must learn to cooperate to finish playing the song. In level 3, an autistic child and a neurotypical child operate eight notes together (two sets of cooperative play toys) to participate in independent and interleaved playing. The score must be in $\mathrm{C}$ major, namely $\mathrm{C}-\mathrm{B}$, and popular songs are primarily used. During each stage and at the completion of the task, the therapist should give appropriate encouragement. During play, the therapist must attempt to guide the participating children to interact and ensure their safety.

Results demonstration stage: The present study recruited two autistic boys (case A was 3-year-old and case B was 4-yearold) (Table 7) and two age-matched neurotypical children, and an occupational therapist conducted one to two therapy ses-

Table 6. Quality function deployment (QFD) analysis result

\begin{tabular}{|c|c|c|c|c|c|c|c|c|c|}
\hline Autism cooperative play toy & 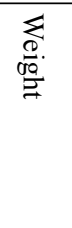 & 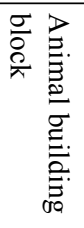 & 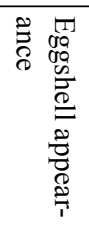 &  &  & 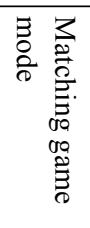 & 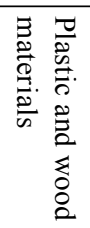 & 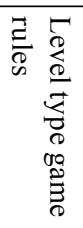 & 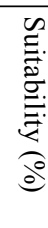 \\
\hline Take turns game mode & 9.3 & 1.1 & 0.5 & 1.1 & 0.5 & 2.5 & 0.8 & 2.2 & 7 \\
\hline Guide the children to actively seek help & 13 & 0.8 & 0.8 & 1.1 & 0.8 & 2.2 & 0.5 & 2.8 & 11 \\
\hline Enhance sound and light effects & 13 & 2.5 & 1.7 & 2.8 & 2.5 & 1.7 & 1.7 & 0.5 & 15 \\
\hline Provide periodic difficulty modes & 7.4 & 0.8 & 1.1 & 1.4 & 0.8 & 2.8 & 0.5 & 2.8 & 7 \\
\hline Attractive shape and bright colors & 7.4 & 2.5 & 2.8 & 0.5 & 2.8 & 1.7 & 2.5 & 1.1 & 9 \\
\hline Teach and guide the children & 14.8 & 1.7 & 1.4 & 1.1 & 1.4 & 1.4 & 0.8 & 2.5 & 14 \\
\hline $\begin{array}{l}\text { Provide multiple game modes and } \\
\text { variable ways to play }\end{array}$ & 7.4 & 1.7 & 0.8 & 1.7 & 1.1 & 2.2 & 0.5 & 2.5 & 7 \\
\hline $\begin{array}{l}\text { Guide the children to interact with } \\
\text { peers and play }\end{array}$ & 13 & 1.7 & 0.5 & 1.4 & 0.8 & 2.8 & 0.8 & 2.8 & 13 \\
\hline Attract interest and attention & 14.8 & 2.5 & 2.5 & 1.1 & 2.5 & 2 & 1.4 & 1.4 & 18 \\
\hline Importance $(\%)$ & & 11 & 7 & 8 & 9 & 16 & 5 & 15 & \\
\hline
\end{tabular}

Table 7. Basic information of the patients tested

\begin{tabular}{ccllll}
\hline $\begin{array}{c}\text { Patient } \\
\text { tested }\end{array}$ & Gender & $\begin{array}{l}\text { Age } \\
\text { (years) }\end{array}$ & Barrier & Pediatric neurology assessment & $\begin{array}{c}\text { Social interaction } \\
\text { behavior }\end{array}$ \\
\hline A & male & 3 & $\begin{array}{l}\text { High-functioning autism } \\
\text { features }\end{array}$ & $\begin{array}{l}\text { Cognitive language, social interaction, and emotional } \\
\text { expression at the borderline of delayed development }\end{array}$ & marginal \\
B & male & 4 & High-functioning autism & $\begin{array}{l}\text { Gross motor and social emotional at the borderline of } \\
\text { delayed development }\end{array}$ & marginal \\
\hline
\end{tabular}


sions for the two groups (a 3-year-old group and a 4-year-old group). The therapist acted as the leader who guided the autistic child and his peer to play together. The four children did not know one another. The degree of interaction between the autistic child and the neurotypical child in the traditional treatment mode was 2.1429 , whereas it was 2.8571 in the cooperative play toy mode. This outcome demonstrated that, after the cooperative play toy was introduced into the play therapy, the degree of interaction between the autistic child and the neurotypical child increased significantly. These results indicated that the cooperative play toy is helpful in autism play therapy.

According to the $\mathrm{C}$ statistics of the active behavior and the response behavior, both cases showed a level trend during the behavior baseline period. After the cooperative play toy was introduced, the active behavior curve showed a significant upward trend. However, although the response behavior improved, the overall level remained flat with outliers. This result showed that the introduction of the cooperative play toy had a significant positive effect on active behavior, but was less effective in altering the responsive behavior. Table 8 shows the $\mathrm{C}$ statistics results. During the baseline period, both the active behavior and the responsive behavior were not significant, indicating that the behaviors remained stable during the baseline period. Similarly, there was no statistical significance in the treatment period, indicating that the observation curve during the treatment period did not display a significant changing trend. However, when the observation results of the baseline period and the treatment period were compared (Table 9), the responsive behavior was not significantly different for case A or B. In contrast, the active behavior was significantly different, indicating that the cooperative play toy had a significant effect on improving the active behavior of autistic children.

\section{DISCUSSION}

In the present study, a prototype of a play therapy aid that is suitable for the HFASD children was successfully developed. The design theory for this cooperative play toy resulted from the summary of a systematic investigation result. First, individual case observations showed that there was little active behavior in autistic children; there was mainly passive behavior. Autistic children will only actively interact with other people when asking for help. Once satisfied, they will return to the closed state. This phenomenon is a typical autistic feature, namely estranged, indifferent and passive behavior ${ }^{27)}$. This result is also consistent with Persona's conclusion, including the lack of verbal interaction, attention, and interest in other things. During observation, when the autistic children lost their therapist's accompaniment and assistance, the active behavior of these children would decrease correspondingly; this phenomenon was consistent with the findings of Odom et al ${ }^{28)}$. Second, during the expert interviews, the game behavior mode of autistic children was mainly regular and involved special and

Table 8. Analysis of active behavior and responsive behavior

\begin{tabular}{lcccccccc}
\hline Behavior types & \multicolumn{4}{c}{ Active behavior } & \multicolumn{3}{c}{ Responsive behavior } \\
\hline Case & \multicolumn{3}{c}{ A } & \multicolumn{2}{c}{ B } & \multicolumn{3}{c}{ A } \\
\hline Period & $\begin{array}{c}\text { Baseline } \\
\text { period }\end{array}$ & $\begin{array}{c}\text { Treatment } \\
\text { period }\end{array}$ & $\begin{array}{c}\text { Baseline } \\
\text { period }\end{array}$ & $\begin{array}{c}\text { Treatment } \\
\text { period }\end{array}$ & $\begin{array}{c}\text { Baseline } \\
\text { period }\end{array}$ & $\begin{array}{c}\text { Treatment } \\
\text { period }\end{array}$ & $\begin{array}{c}\text { Baseline } \\
\text { period }\end{array}$ & $\begin{array}{c}\text { Treatment } \\
\text { period }\end{array}$ \\
\hline Number of observations & 8 & 16 & 8 & 16 & 8 & 16 & 8 & 16 \\
Slope of trend & -0.02 & 1.13 & 0.28 & 0.71 & -0.33 & 0.28 & -0.11 & 0.26 \\
Stability of trend & stable & stable & stable & stable & stable & stable & stable & stable \\
Number range & $0-1$ & $6-35$ & $0-4$ & $2-26$ & $0-4$ & $5-37$ & $1-8$ & $6-27$ \\
Average & 0.13 & 15.38 & 0.75 & 10.75 & 1.25 & 9.31 & 3.37 & 14.43 \\
Beginning and ending values & $0-0$ & $6-12$ & $0-4$ & $12-26$ & $1-0$ & $5-11$ & $4-2$ & $19-24$ \\
C & -0.14 & 0.31 & 0.25 & 0.30 & 0.32 & -0.13 & 0.01 & -0.05 \\
Z & -0.46 & 1.34 & 0.84 & 1.29 & 1.40 & -0.58 & 0.05 & -0.21 \\
\hline
\end{tabular}

Table 9. Comparison and analysis of the periods (treatment period/baseline period) of active and responsive behaviors

\begin{tabular}{lcccc}
\hline Behavior type & \multicolumn{2}{c}{ Active behavior } & \multicolumn{2}{c}{ Responsive behavior } \\
\hline Case & $\mathrm{A}$ & $\mathrm{B}$ & $\mathrm{A}$ & $\mathrm{B}$ \\
\hline Value change & $6-0$ & $12-4$ & $5-0$ & $19-2$ \\
Value difference & +6 & +8 & +5 & +17 \\
Overlap percentage & $0 \%$ & $0 \%$ & $18.75 \%$ & $31.25 \%$ \\
$\mathrm{C}$ & 0.63 & 0.58 & 0.17 & 0.32 \\
$\mathrm{Z}$ & $3.25 * *$ & $2.96 * *$ & 0.91 & 1.68 \\
\hline$* * \mathrm{p}<0.01$ & & & &
\end{tabular}


non-functional norms or play, such as puzzles. This suggestion will be helpful for designing game rules and modes that are suitable for autistic children, to improve their behavior, which lacks active interaction. Additionally, the attractiveness of the toy to autistic children is the most critical feature. Axline and Schaefer suggested that music could help enhance the social and language interaction abilities of autistic patients ${ }^{16}$. Based on the QFD results, the cooperative play toy developed in the present study used music controls, colorful acrylic animal graphics, and varied game modes to enhance sound and light effects and attractiveness.

In the present study, the clinical test results showed that, after the introduction of the cooperative play toy into the autism play therapy, the degree of interaction between the autistic children and their peers increased significantly; for example, although the opinions of the autistic children were different from those of their peers, the autistic children felt confident in actively expressing themselves and did not hesitate to make inquiries. This result showed that the cooperative play toy was effective in improving the interactive ability of autistic children and that these children can benefit from play therapy, as demonstrated by an improved IQ and social interaction. During the test, although the autistic children still could not use clear spoken language to express their emotions and participate in interactions, they used non-verbal language expression as their communication method through the cooperative play toy. This phenomenon is consistent with the suggestion by House that a better interactive atmosphere motivates children to use appropriate methods to express their feelings ${ }^{29)}$. However, because of the limitations of the experimental conditions and the number of experiments, we could only preliminarily confirm the usefulness of the cooperative play toy. However, during the test, the latter halves of the treatment period of both the active behavior and the responsive behavior showed numerical oscillations (sudden increases and decreases). Based on the analysis of the image recording, a likely reason was that the difficulty of the games during the treatment period was increased, causing the game to be interrupted at times and affecting the recording of the numerical values. Based on the $\mathrm{C}$ statistics analysis results, the cooperative play toy significantly improved the active behavior of the autistic children. However, it had a relatively lower positive effect on responsive behavior, potentially because the toy intervention time was too short and the number of observations was insufficient.

In summary, the present study has developed a set of autism cooperative play toys to serve as an interactive bridge between high-functioning autistic children and their neurotypical peers, thereby improving their social skills and further enhancing their life skills. The experimental results showed that this cooperative play toy can significantly improve the degree of interaction between children HFASD and their neurotypical peers, confirming that the cooperative play toy is helpful for enhancing social interaction of autistic children. In future, long-term clinical tests will be conducted to verify the continuous effectiveness of cooperative play toys on the behavior development of HFASD children.

\section{ACKNOWLEDGEMENTS}

This work was supported in part by the Ministry of Science and Technology, Taiwan, ROC under Contract MOST 103-2628-H-182-001-MY2, MOST 103-2221-E-182-048, and MOST 104-2410-H-182-025-MY2, by the Chang Gung Medical Foundation (fund no. CMRPD290063, CMRPD3E0371, and CMRPD3E0372), and by the Healthy Aging Research Centre, Chang Gung University (fund no. EMRPD1E1691, CMRPD1B0331, and CMRPD1B0332). The funders had no role in the study design, data collection and analysis, decision to publish, or preparation of the manuscript. This research also thanks Ms. Cho-Chi Hsu for her early contribution to the manuscript.

\section{REFERENCES}

1) Matson JL, Kozlowski AM: The increasing prevalence of autism spectrum disorders. Res Autism Spectr Disord, 2011, 5: 418-425. [CrossRef]

2) Autism and Developmental Disabilities Monitoring Network Surveillance Year 2008 Principal Investigators Centers for Disease Control and Prevention: Prevalence of autism spectrum disorders-Autism and Developmental Disabilities Monitoring Network, 14 sites, United States, 2008. MMWR Surveill Summ, 2012, 61: 1-19. [Medline]

3) Worley JA, Matson JL: Comparing symptoms of autism spectrum disorders using the current DSM-IV-TR diagnostic criteria and the proposed DSM-V diagnostic criteria. Res Autism Spectr Disord, 2012, 6: 965-970. [CrossRef]

4) Rubin E, Lennon L: Challenges in social communication in Asperger syndrome and high-functioning autism. Top Lang Disord, 2004, 24: 271-285. [CrossRef]

5) Huang AX, Wheeler JJ: High-functional autism: an overview of characteristics and related issues. Int J Spec Educ, $2006,21: 109-122$.

6) Goin RP, Myers BJ: Characteristics of infantile autism: moving toward earlier detection. Focus Autism Other Dev Disabil Autism, 2004, 19: 5-12. [CrossRef]

7) Mastrangelo S: Play and the child with autism spectrum disorder: from possibilities to practice. Int J Play Ther, 2009, 18: 13-30. [CrossRef]

8) Libby S, Powell S, Messer D, et al.: Imitation of pretend play acts by children with autism and Down syndrome. J Autism Dev Disord, $1997,27: 365-383$. [Medline] [CrossRef]

9) Bergen D: The role of pretend play in children's cognitive development. Early childhood Research and Practice, $2002,4: 193-483$.

10) Fall M, Navelski LF, Welch KK: Outcomes of a play intervention for children identified for special education services. Int J Play Ther, 2002, 11: 91-106. [CrossRef]

11) Machalicek W, Shogren K, Lang R, et al.: Increasing play and decreasing the challenging behavior of children with autism during recess with activity schedules and task correspondence training. Res Autism Spectr Disord, 2009, 3: 547-555. [CrossRef] 
12) Naber FB, Bakermans-Kranenburg MJ, van Ijzendoorn MH, et al.: Play behavior and attachment in toddlers with autism. J Autism Dev Disord, 2008, 38: 857-866. [Medline] [CrossRef]

13) Baer DM, Wolf MM: Some still-current dimensions of applied behavior analysis. J Appl Behav Anal, 1987, 20: 313-327. [Medline] [CrossRef]

14) Mesibov GB, Shea V, Schopler E: The TEACCH approach to autism spectrum disorders. New York: Springer, 2004.

15) Jaschke AC: Music intervention as system: reversing hyper systemising in autism spectrum disorders to the comprehension of music as intervention. Med Hypotheses, 2014, 82: 40-48. [Medline] [CrossRef]

16) Axline VM, Schaefer CE: School-Based Play Therapy, 2nd ed. New York: Wiley, 2010.

17) Williams E: A comparative review of early forms of object-directed play and parent-infant play in typical infants and young children with autism. Autism, 2003, 7: 361-377. [Medline] [CrossRef]

18) Wolfberg PJ, Schuler AL: Integrated play groups: a model for promoting the social and cognitive dimensions of play in children with autism. J Autism Dev Disord, 1993, 23: 467-489. [Medline] [CrossRef]

19) Mead M: Sex and temperament in three primitive societies. In: Mead M (ed.), Sex and Gender. New York: Mentor, 1963 , pp $220-225$.

20) Erikson E: Childhood and society. New York: Norton, 1993.

21) Vygotsky LS: Play and its role in the mental development of the child. Soc Psychol, 1967, 12: 1-18.

22) Bruner JS, Goodnow JJ, Austin GA: A study of thinking. New York: Transaction, 2009.

23) Tseng KC: An IPDD approach for systematic innovation of products, processes, and services: a case study on the development of a healthcare management system. The 5th IASDR World Conference on Design Research. Tokyo, 2013.

24) Leung CH: Validation of the Penn Interactive Peer Play Scale with preschool children in low-income families in Hong Kong. Early Child Dev Care, 2014, 184: 118-137. [CrossRef]

25) Johnson JE, Christie JF, Yawkey TD: play and early childhood development, 2nd ed. London: Longman, 1999.

26) Tsai LY: Diagnostic Issues in High-Functioning Autism. In: Mesibov ESGB (ed.), High-Functioning Individuals with Autism. NY: Plenum Press, 1992, pp $11-40$.

27) Wing L, Gould J: Severe impairments of social interaction and associated abnormalities in children: epidemiology and classification. J Autism Dev Disord, 1979, 9: 11-29. [Medline] [CrossRef]

28) Odom SL, Hoyson M, Jamieson B, et al.: Increasing handicapped preschoolers' peer social interactions: cross-setting and component analysis. J Appl Behav Anal, 1985, 18: 3-16. [Medline] [CrossRef]

29) House RJ: Role conflict and multiple authority in complex organizations. California Management Review, 12: 53-60, 1970. [CrossRef] 